\title{
Sistema de Cobertura em Estrutura Metálica Roll-On: um Estudo de Caso
}

\author{
Gabriel Santomé Reis', Marcelo Rocha Haraguchi', Marcelo Tsuyoshi Haraguchi', Fernando Ernesto Ucker', \\ Wilian Fernando Borba ${ }^{2}$, Pedro Daniel da Cunha Kemerich ${ }^{3}$ \\ ' Laboratório de Planejamento e Monitoramento Ambiental - LPMA/UFSM, Curso de Engenharia Ambiental da Universidade Federal de \\ Santa Maria/CESNORS, Frederico Westphalen, Brasil. \\ ${ }^{2}$ Técnico em Agropecuária, Aluno de Graduação do Curso de Engenharia Ambiental, Universidade Federal de Santa Maria, Santa Maria, \\ Brasil. \\ ${ }^{3}$ Coordenador do Curso de Engenharia Ambiental da Universidade Federal de Santa Maria/CESNORS, Frederico Westphalen, Brasil.
}

\begin{abstract}
Resumo
As obras de engenharia civil têm apresentado sistemas industrializados em vários segmentos, neste caso, é apresentada a execução de cobertura em estrutura metálica, que potencialmente se relaciona diretamente com a utilização do método convencional de execução. Este trabalho tem por objetivo viabilizar o uso do Sistema de cobertura em Estrutura Metálica Roll-On. Para alcançar o objetivo, utilizam-se pesquisas específicas bibliográficas de modo a apresentar em obra de grande porte o método de execução de cobertura em estrutura metálica Roll-On, apresentando suas técnicas construtivas, especificações dos materiais, partes integrantes da cobertura e um estudo de caso com apresentação de figuras, a fim de obter uma melhor compreensão das particularidades deste sistema. A obra em estudo será realizada no Shopping Passeio das Águas, localizado na Avenida Goiás com a Perimetral Norte, com aproximadamente $70.000,00 \mathrm{~m}^{2}$ de cobertura em estrutura metálica Roll-On. É considerada uma obra de grande porte muito complexa devido às várias curvas em sua estrutura arquitetônica, aos inúmeros elevadores, às lajes técnicas e às duas Claraboias (obras de arte), que ocasionam descolamentos de prumos, travessas, diferentes padrões de rufos e pingadeiras, além de inúmeros reforços na estrutura da cobertura e vários cortes nas vigas Roll-On. A escolha deste método construtivo para a obra em estudo será abordada no decorrer da revisão bibliográfica, explicando o motivo da aceitação de um projeto totalmente inovador com parâmetros de execução nos quesitos prazo, custo e qualidade distintos em relação ao método mais abrangente no mercado goiano, o convencional.
\end{abstract}

Palavras-chave: Sistema Roll-On, cobertura metálica e elementos

\begin{abstract}
The civil engineering works have shown in several industrial systems segments, as in this case running topping a metallic structure, which potentially relates directly to the use of the conventional method of execution. This work aims to facilitate the use of the system coverage in Steel Structure Roll-On. To achieve the goal, we use specific literature searches in order to submit a work of large method of execution coverage roll-on metallic structure, presenting their construction techniques, material specifications, which cover members of the parties and case study with presentation of figures , getting a better understanding of the particularities of this system. The work will be studied in Shopping Sightseeing Waters, located in Goiás Avenue to North Perimeter, with approximately $70,000.00$ square meters of coverage roll-on metallic structure. It is considered a work of great size, and very complex because of the many curves in its architectural structure, its numerous lifts, technical slabs, and two skylights (Works of Art), which cause many detachments of uprights , beams, different patterns of flashings and drip pans, numerous reinforcements in the roof structure and several cuts on beams Roll -On. The choice of construction method for the project under study, will be addressed during the review, explaining why the acceptance of a totally new design, with execution parameters in the categories of time, cost and distinct quality in relation to the most comprehensive method on the market Goias, conventional.
\end{abstract}

Keywords: Roll-On System, metal cover and elements. 


\section{INTRODUÇ̃̃o}

Para se obter um resultado satisfatório em uma obra, são indispensáveis planejamento, elaboração de projetos, com a concepção do emprego do melhor material, e mão-de-obra qualificada para a finalidade de uso. As estruturas de sistema convencional se baseiam na composição da sua estrutura, as tesouras, que são suas vigas principais, que recebem as cargas devidas ao material de cobrimento, peso próprio das terças, vento e eventuais sobrecargas suspensas, tais como peso dos montadores, luminárias, forros e instalações em geral. Segundo Aisi (2001), as tesouras são compostas por banzos superiores, banzos inferiores, montantes e diagonais. Para o apoio das telhas, colocam-se as terças que são dispostas em ortogonal as tesouras com finalidade de suportar as chapas/telhas da cobertura.

Foi observado que em obras de cobertura com estrutura metálica, no município de Goiânia, como supermercados, galpões e centros automobilísticos, são caracterizadas pela utilização de cobertura convencional, que é uma característica da cultura goiana, restringindo a abertura de novos métodos construtivos. No entanto, também foi possível observar que algumas obras, como Supermercados, foram executadas pelo sistema Roll-on, caracterizado como um sistema pouco difundido.

O objetivo deste trabalho de pesquisa técnica é apresentar o método de execução do sistema Roll-On com suas características construtivas, abordando um projeto detalhado de lançamento da cobertura de uma obra específica, além da identificação e o posicionamento das peças do sistema, sendo este utilizado para vários tipos de edificações, como shoppings, centros de distribuições, supermercados, fábricas, e vãos que, na obra Passeio das Águas, chegam até 30 metros de comprimento, por se tratar de uma construção rápida, limpa e de custo viável.

\section{MATERIAL E MÉTODOS}

O estudo de caso realizado neste trabalho é uma obra localizada na cidade de Goiânia - GO, mais especificamente o Shopping Passeio das Águas, localizado na Avenida Perimetral Norte, esquina com Avenida Goiás, que apresenta a execução da cobertura pelo sistema Roll-On com projetos e concepções bem definidas.

Será detalhado neste trabalho o conceito estrutural Roll-On. Os processos construtivos serão demonstrados e explicados com figuras, visando especificar os equipamentos a serem utilizados, as ferramentas e a sequencia de montagem. A montagem é o coroamento de toda a obra, o que torna possível constatar se houve ou não um bom projeto. Finalmente é exposto um estudo de caso que mostra uma obra durante o seu processo de fabricação, montagem e instalação.

\section{RESULTADOS E DISCUSSÃO}

\section{I Peças integrantes do sistema convencional}

Existem as colunas, elementos que têm a função de transmitir os esforços da estrutura para a fundação; as tesouras ou vigas principais, que recebem as cargas devido aos materiais de cobrimento, peso próprio das terças, possíveis sobrecargas suspensas e ação dos ventos; e os contraventamentos, responsáveis pela rigidez da estrutura decorrente dos esforços que a estrutura recebe de seus elementos e da ação do vento.

As terças e vigas de chapamentos são terças dispostas horizontalmente, servindo de apoio para as chapas de tapamento que estão sujeitas à flexão dupla, no sentido de maior inércia, provocado pela ação dos ventos, e, no sentido de menor inércia, provocado pelo peso próprio. As terças se encontram situadas entre vigas principais e secundárias de pórticos ou tesouras, também com a finalidade de suportar as chapas de tapamento e as chapas de cobertura, que apresentam a função de proteger a estrutura de intempéries. Em alguns casos onde existe a necessidade de isolamento térmico, faz-se uso das chapas sanduíches, compostas por duas ou mais chapas separadas pelo material isolante.

\subsection{Apresentação do conceito estrutural do sistema Roll-On}

O conceito de sistema de cobertura se traduz pela integração da estrutura e do telhado, tratando a cobertura como um conjunto, e não como partes distintas como se convencionava (MARKO, 2004). O sistema Roll-On é um sistema integrado de estrutura e cobertura metálica. São treliças paralelamente dispostas, sobre as quais são desenroladas bobinas contínuas de aço sem emendas, furos ou sobreposições, criando canais com o comprimento total da cobertura. É um sistema estanque e de alta segurança, permitindo caimentos de até $1 \%$, sendo o resultado de um projeto detalhado, um processo de fabricação industrial e uma montagem em linha de produção.

Em toda construção existe a necessidade de instalações de redes elétricas, hidráulicas, de incêndio, de refrigeração, entre outras. Os módu- 
los estruturais do Sistema Roll-On são dispostos paralelamente, formando uma malha de apoios próprios para recebê-las sem improvisações, já que possuem furações específicas para essas finalidades. O uso dessa facilidade elimina estruturas de apoio complementares e proporciona maior agilidade na montagem, reduzindo o tempo total da construção (MARKO, 2004).

O sistema se diferencia em três modelos estruturais: o Roll-On 90, 120 e 150, variando apenas a altura, o afastamento ou a espessura dos módulos. Os produtos são capazes de vencer diferentes vãos e sobrecargas de acordo com as necessidades de um projeto, de modo que os detalhes construtivos que completam o produto sejam sempre compatíveis.

\subsection{Peças do sistema (elementos estruturais)}

As peças integrantes do sistema de cobertura Roll-On, formados por inúmeros elementos estruturais, são dimensionados conforme NBR 8.800 (ABNT, 1986), que se baseia no método dos estados limites e fixa as condições exigíveis que devem obedecer ao projeto na execução e na inspeção de estrutura de aço para edifícios, que podem ser executados com perfis laminados ou soldados, não híbridos e com ligações feitas por parafusos e soldas. Perfis não híbridos são aqueles cujos elementos componentes são do mesmo aço.

\subsection{Bobinas (Chapas Zincadas Galvanizadas)}

As bobinas são feitas em chapas de aço revestido (galvanizado, galvalume ou pré-pintado) com espessura de $0,65 \mathrm{~mm}$, que são desenroladas sobre os módulos estruturais, formando canais contínuos de condução da água com caimentos mínimos. Possuem a função de dar estanqueidade a cobertura e pode-se obter qualquer comprimento, sendo definido pelo vão a ser coberto.

\subsection{Cobrejuntas}

As cobrejuntas têm por finalidade realizar o cobrimento dos banzos superiores, servindo como uma telha cumeeira para dar estanqueidade entre os vãos das bobinas. São feitas a partir de chapas de aço (galvanizado, galvalume ou pré-pintado) de $0,65 \mathrm{~mm}$, tendo o formato parecido com a das telhas cumeeiras, com comprimento de $2,45 \mathrm{~m}$ e $3,05 \mathrm{~m}$.

\subsection{Cintas}

As cintas possuem função estrutural e servem de suporte para o desenrolamento das bobinas, que ficarão apoiadas sobre as cintas. São fixadas nos banzos superiores de $1,20 \mathrm{~m}$ à $1,20 \mathrm{~m}$ de espaçamento, sendo dimensionadas para receber as cargas das bobinas e outras sobrecargas provenientes da cobertura. As cintas são em chapa de aço (galvanizado, galvalume ou pré-pintado) de $0,65 \mathrm{~mm}$.

\subsection{Diagonais}

As diagonais são peças do módulo estrutural (galvanizado, galvalume ou pré-pintado) de $1,95 \mathrm{~mm}$ de espessura, utilizadas para unir o banzo superior com o banzo inferior, sendo as peças dispostas em diagonal formando as vigas/ treliças, dando resistência mecânica ao módulo.

\subsection{Travessas}

As vigas são montadas aos pares para que, assim, possam ser elevadas à cobertura. Para a formação dos pares, usam-se travessas que são colocadas em forma de Z, como indicado no projeto de lançamento, realizando o travamento das vigas que dá rigidez aos pares e ao seu conjunto estrutural da cobertura. São feitas em chapa de aço (galvanizado, galvalume ou pré-pintado) com $1,55 \mathrm{~mm}$ de espessura.

\subsection{Suporte para cobrejuntas}

Para a fixação dos cobrejuntas nos banzos superiores é utilizado o suporte de cobrejunta. Após o desbobinamento, deve-se encaixar o suporte de cobrejuntas em rasgos apropriados nos banzos, sempre sobre os escudos a cada 1,20 m. São feitas em chapas de aço (galvanizado, galvalume ou pré-pintado), de $1,55 \mathrm{~mm}$.

\section{10 Banzos}

Os banzos são vigas metálicas que tem como função resistir aos momentos fletores. São feitas em chapa de aço (galvanizado, galvalume ou pré-pintado) com 1,55mm e 1,11 mm de espessura, conforme necessidade para atender a cada projeto.

\section{II Contradiagonais}

As contradiagonais têm como finalidade reduzir o comprimento da flambagem das diagonais, aumentando a sua capacidade de carga. São feitas em chapa de aço (galvanizado, galvalume ou pré-pintado) de $1,55 \mathrm{~mm}$.

Algumas observações importantes devem ser feitas sobre as contradiagonais:

- A fixação das contradiagonais é feita dos dois lados da diagonal, conforme mostra a figura 2 ;

- As contradiagonais devem ser fixadas de boca para cima;

- O Roll-On 120 e o Roll-on 150 sempre 
levam contradiagonais;

- O Roll-On 90 só utiliza contradiagonais em casos especiais.

\subsection{Chapas de ligação}

Servem para unir os módulos através de seus banzos e podem ser de dois tipos: aberta ou fechada. Na chapa de ligação aberta, a distância entre os furos centrais é maior do que a correspondente na chapa fechada.

Em geral, colocam-se as chapas abertas nos banzos superiores, e as fechadas nos inferiores. Assim, o banzo superior da viga fica um pouco maior, formando uma leve contra flecha.

\section{I 3 Execução de montagem do Sistema Roll-On}

$O$ processo de montagem se define pela sequência de operações e os tempos correspondentes, considerando a montagem como ato de unir as peças que vão compor uma estrutura final, conforme especificado nos desenhos de projeto (BELLEI, 2000).

Para uma montagem ideal é necessário atingir os níveis de rapidez, adaptabilidade e compatibilidade com os projetos de lançamento característicos do sistema Roll-On. Como a maioria das coberturas em estrutura metálica, as partes integrantes da cobertura chegam na obra em peças separadas, sendo necessário todo o processo de montagem executado in loco. Serão abordados toda a sequência de montagem das peças integrantes, os processos de elevação, o travamento das vigas, o desenrolamento das bobinas e os detalhes construtivos para que se tenha o produto final, a cobertura.

\section{14 Pré-Montagem das vigas}

1 Passo - Colocar os banzos superiores e inferiores no gabarito e, em seguida, as diagonais e contradiagonais (quando houver) com os parafusos e porcas, seguindo os tamanhos determinados pelo projeto de lançamento, dando, assim, origem aos módulos.

2 Passo - Execução de aperto dos parafusos e porcas das diagonais e contradiagonais. Finalizado o modulo, o processo se inicia novamente, tendo assim uma produção em série. Os módulos finalizados serão estocados de forma empilhada em cima de paletes ou caibros, de modo a não ultrapassar 10 módulos.

\subsection{Montagem das vigas e execução de travamentos em pares}

1 Passo - Executar a emenda dos módulos, através das chapas de ligação.

2 Passo - Repetir o 1 passo sucessivamente até o comprimento total da viga.

3 Passo - Providenciar o aperto dos parafusos da diagonal de emenda e chapas de ligação.

4 Passo - As vigas prontas são retiradas do gabarito e estocadas na horizontal, como foi feito com os módulos.

5 Passo - Após a conclusão de todas as vigas do trecho correspondente, colocá-las dispostas paralelamente para que se inicie a instalação das travessas, formando pares de vigas, e, em seguida, realizando o aperto dos parafusos e porcas das travessas, dando rigidez aos pares para que possam ser elevados.

\section{16 Preparação da obra para receber as Vigas}

É necessário observar, antes da elevação, se na obra os pilares e as vigas que servirão de apoio para a estrutura da cobertura apresentam o nível indicado em projeto, para que não haja interferências nos caimentos da cobertura.

Com o auxílio de topógrafos, é locado e marcado o gabarito para o ponto inicial de apoio do primeiro par. O restante dos pares serão elevados e travados a este par, que é ponto de referência naquele trecho.

\section{17 Início das elevações e posicionamento das vigas Roll-On}

Através de caminhão munck e/ou guindastes e o auxilio de montadores é iniciado o processo de elevação dos pares de vigas. Os pares de vigas são colocados encostados uns aos outros, sem a preocupação de posicioná-los nos locais onde ficarão definitivamente. Com isso, diminui o tempo de elevação e, consequentemente, o custo do caminhão munck ou guindaste.

Se, por acaso, houver um número ímpar de vigas, uma delas ficará sem par. Esta viga será chamada de "singela". Para elevar uma viga singela, deve-se fixar a viga externa do primeiro ou do último par de vigas a ser elevado; com ela bem amarrada, elevam-se as três vigas. Enquanto as vigas não estiverem fixadas em seus lugares definitivos é necessário mantê-las amarradas com cordas às vigas de apoio, para evitar que, sob a ação do vento, as vigas venham a cair.

Após a elevação de todos os pares de vigas correspondentes ao trecho do projeto, seguindo a orientação de lançamento da obra inicia-se o posicionamento das vigas em locais definitivos. 
Deve-se identificar a posição da primeira viga seguindo a indicação no projeto pela orientação do gabarito feito pelo topógrafo. Com o primeiro par de vigas em sua posição, passamos a distribuí-los colocando a travessa inferior da região dos apoios. Dessa forma, é garantido o espaçamento certo entre os pares de vigas.

\section{I Alinhamento das vigas e soldagem na viga de apoio.}

Com uma linha de nylon, procede-se ao alinhamento de todas as vigas. Após garantir o posicionamento da primeira e da última viga, fixase a linha em determinado ponto da primeira viga e no mesmo ponto na última. Estes pontos podem ser um dos furos dos banzos superiores. Feito isto, as demais vigas são obrigadas a ficar com o ponto / furo correspondente, debaixo da linha [9]. Dessa forma, todas as vigas estarão alinhadas e preparadas para o complemento das travessas que faltam (as duas do apoio) e, consecutivamente, a soldagem nos apoios.

\section{19 Complementação das travessas e soldagem dos banzos inferiores nas vigas de apoio}

Para a complementação do travamento das vigas é necessário que se coloque as travessas nas diagonais que chegam ao apoio pelo lado do vão, fazendo com que a linha de travessas forme uma viga treliçada nas diagonais, pois é ela que estará recebendo e suportando a maior carga, distribuindo para os apoios.

Instaladas todas as travessas, faz-se necessária a soldagem dos banzos inferiores nas vigas de apoio, para que haja resistência ao cisalhamento e para que as vigas submetidas a forças atmosféricas não venham a sair do alinhamento ou a cair.

\subsection{Colocação das cintas}

Após a soldagem de todas as vigas, o trecho está pronto para receber as bobinas na cobertura. Primeiramente são instaladas as cintas nos banzos superiores. Cada cinta possui uma pequena mossa próxima a cada extremidade. Essa mossa serve para indicar o local em que a cinta deve ser fixada ao banzo.

É necessário seguir os seguintes passos: primeiro posicionar as mossas de cada cinta em furos de banzos adjacentes; segundo, com uma punção, furar as cintas nos locais das mossas e, por último, rebitar cada furo aberto, fixando as cintas ao banzo.

A primeira cinta deverá ser colocada no primeiro furo do banzo, a segunda a $30 \mathrm{~cm}$ da $1^{\circ}$, no próximo furo. Na sequência, coloca-se uma cinta a cada $120 \mathrm{~cm}$ até o final da viga, e deve-se colocar uma cinta a $30 \mathrm{~cm}$ da última, como foi feito no início. Dessa forma, as regiões da cabeça e da pingadeira de cada bobina ficarão reforçadas.

\subsection{Elevação das bobinas e o desbobinamento}

As bobinas são elevadas imediatamente em seus lugares, não se esquecendo de observar a direção do desbobinamento. Com o auxilio de um suporte, podendo ser de madeira ou de metal, desenrola-se a bobina e, com o suporte, alinha-se até desenrolar totalmente a bobina. Por fim, dobram-se as cintas por cima da bobina desenrolada.

\subsection{Instalação das cobrejuntas}

Após o desbobinamento deve-se encaixar o suporte de cobrejuntas em rasgos apropriados nos banzos, sempre sobre os escudos e a cada 1,20 m. Após a fixação com as orelhas, os suportes estarão preparados para a colocação dos cobrejuntas.

Os cobrejuntas devem ser montados a partir da pingadeira, em direção à cumeeira, colocando o furo maior no lado da cumeeira. Os cobrejuntas deverão ser superpostos no sentido do caimento e a sua fixação ocorrerá, no mínimo, em dois pontos distintos. O furo maior estará obrigatoriamente por baixo na área de sobreposição.

\subsection{Fechamentos padrão}

Sempre que houver uma cumeeira ou um rufo, será preciso fechar a extremidade da bobina. Nesses casos, ao iniciar o desbobinamento, deve-se realizar o corte, as dobras na bobina e a colocação das cabeceiras.

A pingadeira é formada apenas por uma peça, é montada na estrutura da cobertura, nos banzos, e serve para cascata para qualquer tipo de calha. Ela é instalada no final da bobina e presa uma a outra conforme o número de vãos.

\subsection{Planejamento}

O planejamento de montagem das estruturas metálicas convencionais é utilizado para garantir a forma mais rápida, segura e eficiente, a fim de otimizar o trabalho, garantindo segurança e eficiência.

O planejamento deve ser um estudo minucioso de modo a facilitar o trabalho de campo, porém, respeitando os limites de segurança. Deve conter ainda todos os dados necessários como, por exemplo, custos adicionais. Esse planejamento deve estar presente no canteiro de obras para garantir a execução correta. 


\subsection{Sequência de Montagem}

1. Montagem das colunas dos vãos de contraventamentos;

2. Montagem dos contraventamentos verticais;

3. Montagem das vigas de beiral e de tapamento da interligação entre colunas;

4. Montagem da viga de pórtico entre as colunas do primeiro eixo;

5. Estaiamento desse pórtico;

6. Montagem da segunda viga de pórtico; 7. Interligação do primeiro e do segundo pórtico com as terças de cobertura;

8. Montagem do contraventamentos do plano de cobertura;

9. Remoção dos estais, montagem dos demais eixos repetindo a seguinte sequência;

10. Montagem das colunas vizinhas ao vão de contraventamento;

11. Montagem das vigas de beiral e de tapamento de interligação entre as colunas; 12. Montagem de viga de pórtico entre as colunas;

13. Interligação do núcleo contraventado com o novo pórtico montado as terças de cobertura.

\section{Conclusão}

Com esse trabalho pode-se perceber que o sistema de cobertura Roll-On é um sistema para grandes construções, indicado para os mais diversos segmentos, tais como centros de distribuição, shopping centers, indústrias, hipermercados, terminais rodoviários, entre outros. Esse sistema tem características exclusivas na concepção de coberturas metálicas, integrando estrutura e telhado no mesmo produto, tratando a cobertura como um conjunto, e não como uma parte distinta do sistema.

\section{REFERÊNCIAS}

ABNT - Associação Brasileira de Normas Técnicas. NBR 8800: Projeto e execução de estruturas de aço de edifícios (método dos estados limites). Rio de Janeiro, 1986.

AISI - American Iron and Steel Institute. AISI 2001: Especificação norte americana para o Projeto de aço formados a frio, de elementos estruturais de aço.
Washington, DC, 2001.

Marko Sistemas Metálicos. Produtos Roll-on. [S.1.], 2004. Disponível em: <http://www.marko.com.br/ rollon_cobertura.asp>. Acesso em: 21 abril 2013.

QUIÑONES, B. J. C. Execução de cobertura em estrutura metálica, São Paulo - SP. UAM, 2006. Monografia. 